\title{
Management of horizontal root fracture: two case reports
}

\author{
Dr. Nikhil Mankar*, Dr. Nitin Jogad**,Dr. Ashwin Chute***, Dr. Sanjay \\ Patil****, Dr. Vandana Gade*****, Dr. Sagar Mohkar******* \\ *Post Graduate Student, Dept of Conservative Dentistry and Endodontics, Swargiya Dada Saheb Kalmegh \\ Smruti Dental College and Hospital, Wanadongri, Hingna (Nagpur). \\ ** Post Graduate Student, Dept of Conservative Dentistry and Endodontics, Swargiya Dada Saheb Kalmegh \\ Smruti Dental College and Hospital, Wanadongri, Hingna (Nagpur). \\ ***Reader, Dept of Conservative Dentistry and Endodontics, Swargiya Dada Saheb Kalmegh Smruti Dental \\ College and Hospital, Wanadongri, Hingna (Nagpur). \\ ****Professor, HOD and guide, Dept of Conservative Dentistry and Endodontics, Swargiya Dada Saheb \\ Kalmegh Smruti Dental College and Hospital, Wanadongri, Hingna (Nagpur). \\ ***** Professor and guide, Dept of Conservative Dentistry and Endodontics, Swargiya Dada Saheb Kalmegh \\ Smruti Dental College and Hospital, Wanadongri, Hingna (Nagpur). \\ ****** Post Graduate Student, Dept of Conservative Dentistry and Endodontics, Swargiya Dada Saheb \\ Kalmegh Smruti Dental College and Hospital, Wanadongri, Hingna (Nagpur).
}

\begin{abstract}
Traumatic dental injuries often occur to the teeth and their supporting tissues and they are the main reasons for emergency visit to a dental clinic. Horizontal root fractures usually are characterized by a fracture line that is perpendicular to the long axis of the root. Root fractures are diagnosed through clinical and radiographic examination. Treatment depends on the position of the fracture, the extent of root involvement, correct diagnosis, clinical management, and radiographic follow-up. This article describes the successful management of intraalveolar horizontal, apical root fracture treated with Mineral trioxide aggregate (MTA) barrier and Ellis class III and middle root fracture treated by using fiber post\& core.
\end{abstract}

Key words: Ellis class III fracture, Fiber post, Intraalveolar horizontal root fracture, Mineral trioxide aggregate.

\section{Introduction:}

Traumatic injuries occur more commonly in young patients and vary in severity from enamel fracture to avulsions. Among dental trauma root fracture are relatively common and comprise 0.5 to $7 \%$ of all injuries affecting permanent dentition. ${ }^{[1-3]}$ They are defined as fracture involving dentin, cementum \& pulp. ${ }^{[1]}$ Root fracture are commonly seen in maxillary central incisor of male patient and more frequently at the middle third of the root followed by apical \& coronal third fracture. ${ }^{[4]}$ Intraalveolar root fracture present as either horizontal (also called transverse) or diagonal (also called oblique) or vertical. The clinical presentation of horizontal root fracture may vary from an extruded or displaced crown to a clinically normal tooth.

Diagnosis of root fracture is accomplished by clinical \& radiographic examination. Clinical examination includes the evaluation of mobility, the presence or absence of tenderness \& pain to palpation of the soft tissues, percussion of the teeth \& pulp testing. Radiographic examination must be performed carefully. Two or three radiograph taken at various angle may be needed because of the angulation of the fracture. If the $\mathrm{X}$-ray beam doesn't pass directly through the fracture line it usually cannot be seen on the radiograph. ${ }^{[5]}$

The initial treatment consists of the repositioning of displaced coronal segments, followed by the stabilizing of the tooth to allow healing of the periodontal ligament supporting the coronal segment to occur. ${ }^{[1]}$ Several factors may influence the type of healing includes the stage of root development, mobility and dislocation of the coronal fragment $\&$ diastases between fragments. ${ }^{[8]}$

Anderson \&Hjorting-Hanser described four type of healing sequale. ${ }^{[6,7]}$

1. Healing with calcified tissue. 2. Healing with interproximal connective tissue. 3. Healing with interproximal bone $\&$ connective tissue. 4 . Interproximal inflammatory tissue without healing.

Endodontic intervention is required for non-healing fractures. The current recommendation for midroot, apical root fracture is root canal treatment of the coronal segment only, if this segment shows no mobility ${ }^{[9]}$ No treatment guidelines are available for a tooth showing increased mobility, other than extraction and subsequent replacement with prosthesis. Although the outcome of a root fracture is generally favourable (60-80\% cases), complications such as pulpal necrosis, radicular resorption and pulp canal obliteration can arise ${ }^{[10]}$ Therefore, after performing the adequate clinical management, following up the patients for clinical assessment of treatment success is crucial. 
This case reports describe the successful management of intraalveolar horizontal apical root fracture with extrusion of coronal segment of teeth treated with Mineral trioxide aggregate (MTA) barrier and effective management of Ellis class III and mid-root fracture of tooth by using fiber post and core.

\section{Case 1 Apical Root Fracture With 41, 42 \& 31}

A 40-year-old female patient reported with the chief complaint of pain, mobility \& extrusion of teeth in lower front region of jaw for the last 2 months. Patient had history of frontal impact due to fall from bike about 2 month back. On clinical examination teeth $31,41 \& 42$ showed grade II mobility with extrusion[ fig 1a ]. Teeth were tender on percussion; probing depth was $2 \mathrm{~mm} \&$ demonstrated no response to vitality test (thermal \& electrical test). Intraoral periapical radiograph showed transverse radiolucent line at the apical one third of the root with gap in between two segments was seen[ fig1b ].

On basis of clinical and radiographic finding, diagnosis of irreversible pulpitis with horizontal root fracture in relation to $31,41 \& 42$ was made.

Treatment plan comprised of reduction, semirigid splinting and endodontic treatment of only the coronal fragment in relation to $31,41 \& 42$, as the fracture fragments were not approximated and the possibility of the apical fragment retaining pulp vitality as well. Teeth $31,41 \& 42$ were splinted labially [ fig $1 \mathrm{c}$ ] with fiber splint (Interling, Angelus, Brazil) which was bonded to tooth surface with composite resin. Endodontic therapy was initiated access was gained through lingual surface of teeth $31,41 \& 42$, pulp chamber was irrigated with $2.5 \% \mathrm{NaOCl} \&$ Saline. Working length was determined [ fig1d], cleaning and shaping was completed. Calcium hydroxide Intracanal medicament was placed. Patient was recalled after two week. MTA (Angelus, Brazil) plug was placed into apical $4 \mathrm{~mm}$ of the coronal fragment. After 24 hours rest of canal was obturated with warm vertical compaction of gutta-percha (Calamus, Denstply). Access cavity was sealed with composite resin. Patient post operative course was uneventful. Splint was removed after 4 week \& mobility was within normal limits. At recall visits teeth were asymptomatic and responded normally to palpation and percussion. The patient was reviewed at 3 months [ fig1e ], 6 months [ fig 1f ], 1 year [ fig 1g ]. There was evidence of healing at the fracture line in relation to $31,41 \& 42$ with normal periapical features.

Figure 1
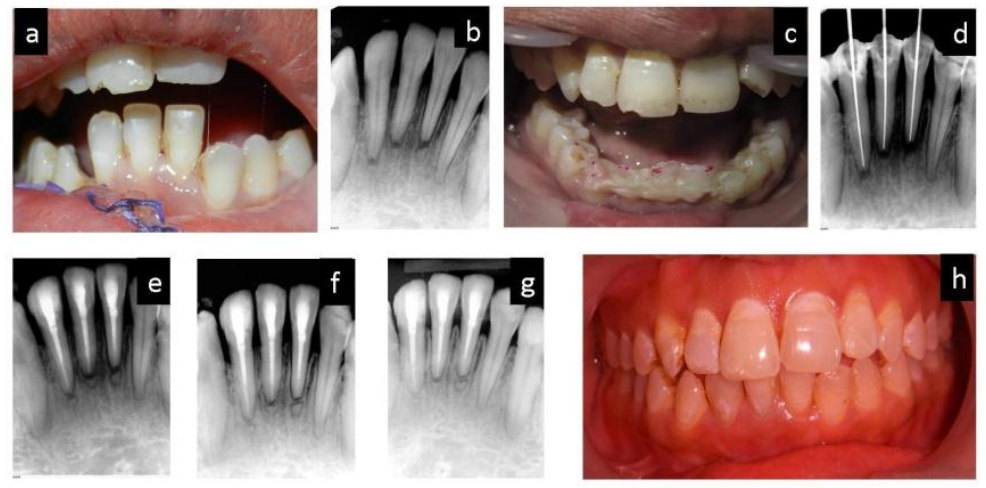

Figure 1: (a) Preoperative clinical photograph, (b) Preoperative radiograph showing fracture line at apical third of root with 31, $41 \& 42$, (c) Fiber splinting done with 31, $41 \& 42$,(d) Working length radiograph with 31, 41 \& 42, (e) Post treatment radiograph, (f) follow up radiograph after 3 month, (g) Follow up radiograph after 1 year. (h) Post operative clinical photograph.

\section{Case 2 Mid-Root Fracture With 11}

A 16-year-old male patient reported with the chief complaint of pain and broken tooth in upper front region of jaw since 2 month. Clinical examination revealed Ellis class 3 fracture \& grade I mobility with 11 [ fig2a ]. Sinus opening was seen buccally in relation with 11. Tooth was tender on percussion with the history of root canal treatment having been attempted in private clinic about 3 days back. Intraoral periapical radiograph showed horizontal mid-root fracture with radiolucency around fracture line and radiopaque root canal filling with $11[$ fig $2 b$ ].

Treatment plan comprised of re-root canal treatment of apical and coronal fragments followed by fiberpost and core by holding both fracture fragments. Old obturation material was removed with RC solve and $\mathrm{H}$ files. Cleaning and shaping was done upto working length determined by intraoral periapical radiograph. $1 \%$ Sodium hypochlorite and saline was used as irrigating solution during preparation. The root canal was finally irrigated with $2 \%$ chlorhexidine. Calcium hydroxide intracanal medicament was placed for 2 weeks. At next 
appointment tooth was asymptomatic and sinus was healed. Root canal was irrigated with EDTA liquid and obturation was done with gutta-percha \& resinoseal sealer [ fig2c ]. The post space was prepared with pessoreamer. Selected fibre post was luted into the root canal holding both coronal and apical fragment of root with dual cure resin cement (Luxacore, DMG) [ fig2d ]. The core build up was done with composite resin [ fig2e ].

In follow up visit tooth mobility was reduced and tooth was clinically asymptomatic. The patient was reviewed at 3 months [ fig2f ], 6 months [ fig 2g ], 1 year [ fig $2 \mathrm{~h}$ ], and 2 year [ fig 2i ] with no signs or symptoms.

\section{Figure 2}
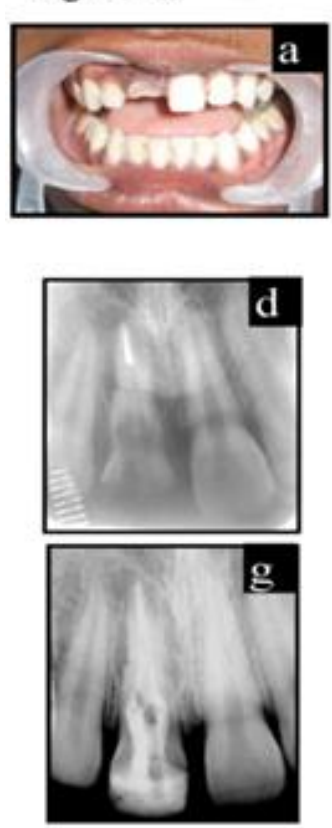
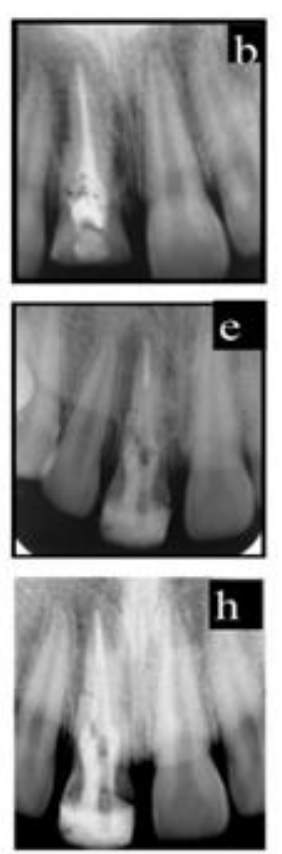
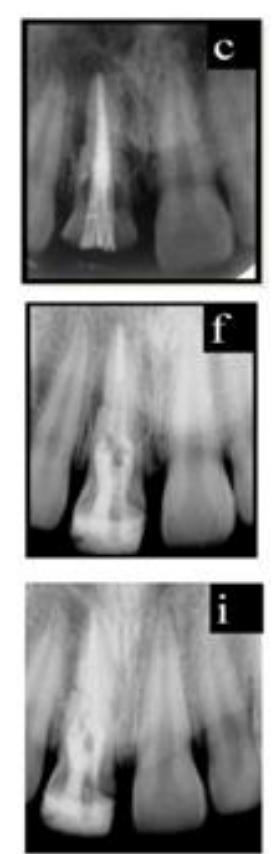

Figure 2 : (a) Preoperative clinical photograph, (b) Preoperative Radiograph mid-root fracture with radiolucency around fracture line, (c) Post-obturation radiograph with 11 ,(d) Fiber post trial radiograph, (e) Post treatment radiograph, (f) follow up radiograph after 3 month, (g) Follow up radiograph after 6 month, (h) follow up radiograph after 1 year, (i) Follow up radiograph after 2 year.

\section{Discussion:}

Root fracture is a complex injury to the periodontal ligament, pulp, dentin and cementum. The injury to the coronal segment can be considered a luxation injury, with resultant trauma to the periodontal ligament and neurovascular supply to the coronal pulp. The apical fragment remains essentially uninjured. To facilitate healing, optimal repositioning and stabilization of teeth is considered essential. ${ }^{[1]}$

Basically, four types of conservative endodontic treatment have been described. ${ }^{[1,12]}$ They are i) cleansing and gutta-percha (GP) filling of the root canal of the coronal fragment only, ii) cleansing and filling of the root canal in both fragments, iii) cleansing and GP filling of the root canal of the coronal fragment and surgical removal of the apical fragment, and iv) treatment of the root canal with calcium hydroxide followed by filling with GP.

The treatment plans of these cases were based on the relationship of fracture line with the bone level.

In the case I, Fiber splint was used to immobilise the teeth within physiologic limit which prevent it from ankylosis. Teeth $31,41 \& 42$ had lost its vitality, probably due to extrusion of coronal fragment. Radiographically, space between the fragments was persistent even after splinting, suggestive of granulation tissue preventing reduction. When pulp necrosis develops, the apical part of the fractured tooth usually remains vital. So, root canal treatment was initiated limiting to coronal segment. ${ }^{\text {[7] }}$

However, it is difficult to seal this fragment because an apical stop is often difficult to achieve, the use of MTA in teeth have been recommended. ${ }^{[13]}$ Studies have observed higher fracture resistance, higher clinical and radiographic success at inducing apical closure, and absence of signs of clinical and radiographic failure, greater amount of hard tissue formation and a lower level of inflammation when MTA-filled root canals are compared with root canals filled with calcium hydroxide. ${ }^{[14]}$ Hence, MTA was selected in the root canal treatment of the present horizontal root fracture, because its use might improve the outcome of the treatment. If total closure (root end) is considered the ideal goal to be reached after the treatment, the results obtained with MTA fulfilled this goal very well. Follow up radiograph of this case report confirmed repair of root fracture 
with mostly hard and connective tissue interposition and there were no sign of resorption or periapical pathology.

In the case II, The fracture line was apical to the alveolar crest level, splinting of both the fragments was carried out. Post space preparation was done involving both coronal and apical fragments leaving $4 \mathrm{~mm}$ of apical guttapercha.

Glass fiber post was used as it is aesthetic, high fatigue strength, high tensile strength and modulus similar to that of the dentin. ${ }^{[15]}$ The beneficial result of root canal treatment with calcium hydroxide was probably because of its antibacterial effect and its ability to promote healing at fracture line.

Fiber post was used which certainly favour the union and stabilization of the two root segments. At 2 years follow up radiograph tooth showed healing at fracture fragment and tooth was asymptomatic.

\section{Conclusion}

The primary purpose of the treatment of fractured elements is to keep a steady tooth and, when it's possible its vitality. It is important to remember that the maintenance of a natural tooth during growth could be an excellent intermediate solution before implant rehabilitation. The clinician must judge every situation on its individual merits and select a procedure that fulfils the needs of the case while maximizing stability and minimizing mobility.Adopting appropriate treatment strategy of using fiber post and core to restore middle third fractures and using material like MTA, for treatment of horizontal fracture at apical third can result in optimum healing and prolonged retention of the teeth,which would otherwise require extraction.

\section{References:-}

[1]. Andreasen FM, Andreasen JO. Crown fractures. Textbook and Color atlas of traumatic injuries to the teeth. 3rd ed. Copenhagen: Munksgaard; 1994:219-56.

[2]. Davidovich E, Heling I, Fuks AB. The fate of a mid-root fracture: a case report. Dent Traumatol 2005;21:170-3

[3]. Caliskan MK. Prognosis of large cyst-like periapical lesions following nonsurgical root canal treatment: a clinical review. IntEndod J 2004;37:408-16.

[4]. KaanOrhan, DDS, PhD,UmutAksoy, DDS, †and AtakanKalender, DDS, PhD,Cone-Beam Computed Tomographic Evaluation of Spontaneously Healed Root Fracture.JOE - Volume 36, Number 9, September 2010

[5]. Patel S, Dawood A, Whaites E,Pittford T et al. New dimensions in endodontic imaging: part 1. Conventional and alternative radiographic systems. IntEndod J 2009;42:447-62.

[6]. Andreasen JO, Hjörting-Hansen E. Intraalveolar root fractures radiographic and histologic study of 50 cases. Oral Surg Oral Med Oral Pathol 1967;25:414-26.

[7]. Johnson BR, Jensen MR. Treatment of a horizontal root fracture by vital submergence. Endod Dent Traumatol 1997; 13:248-50.

[8]. Artvinli LB, Dural S. Spontaneously healed root fracture: report of a case. Dent Traumatol 2003;19:64-6.

[9]. Flores MT, Andersson L, Andreasen JO, Bakland LK, Malmgren B, Barnett F et al. (2007). Guidelines for the management of traumatic dental injuries. I. Fractures and luxations of permanent teeth. Inter national Association of Dental Traumatol, 23(2): 6671.

[10]. Andrade ES, de Campos Sobrinho AL, Andrade MG, Matos JL. Root healing after horizontal fracture: a case report with a 13-year follow up. Dent Traumatol 2008;24:1-3.

[11]. Michanowicz AE. Root fractures. A report of radiographic healing after endodontic treatment. Oral Surgery Oral Medicine Oral Pathology Oral Radiology and Endodontology1963;16:1242-1249.

[12]. Cvek M. Treatment of non-vital permanent incisors with calcium hydroxide IV. Periodontal healing and closure of the root canal in the coronal fragment of teeth with intraalveolar fracture and vital apical fragment. Odontologisk Revy 1974; 25: 239-246.

[13]. Yildirim T, Gencoglu N. Use of mineral trioxide aggregate in the treatment of horizontal root fractures with a 5-year follow up: report of a case. J Endod 2009;35:292-5.

[14]. Hatibovic-Kofman S, Raimundo L, Zheng L, Chong L,Friedman M, Andreasen JO. Fracture resistance and histological findings of immature teeth treated with mineral trioxide aggregate. Dent Traumatol 2008;24:272-6.

[15]. Aquaviva S. Fernandes, SharatShetty, Factors determining post selection: A literature review (J Prosthet Dent 2003; 90:556-62.) 